\title{
COMO OS DOCENTES DE CURSOS TÉCNICO INTEGRADOS COMPARTILHAM A GESTÃO DA INDISCIPLINA
}

\author{
I. A. A. RODRIGUES ${ }^{*}$, M. M. C. GOMES e L. C. MARQUES \\ Instituto Federal de Educação, Ciência e Tecnologia da Paraíba \\ Icaro.rodrigues@ifpb.edu.br
}

Submetido 08/agosto/2015 - Aceito em 05/agosto/2017

DOI: 10.15628/holos.2017.3301

\section{RESUMO}

A indisciplina é um fator presente no âmbito educacional e, por ter uma complexidade de causas que a propiciam, requer um trabalho em conjunto de todos os atores educacionais. Para tanto esta pesquisa de campo e explicativa tem como objetivo investigar, por meio de questionário, como os docentes que lecionam nos Cursos Técnicos Integrados ao Ensino Médio do Instituto Federal de Educação, Ciência e Tecnologia da Paraíba - Câmpus Campina Grande gerenciam a indisciplina em sala de aula, mais especificamente como ocorre a gestão compartilhada dos comportamentos indisciplinados dos discentes em sala de aula, entre professores e demais setores e agentes educacionais desta instituição. Os resultados apontam que a maior parte dos professores investigados não solicita auxílio para tratar de questões de indisciplina, e para aqueles que costumam solicitar ajuda apenas raramente o fazem, assim como a Coordenação Pedagógica, a Coordenação de Assistência ao Estudante e as Auxiliares Educacionais são as principais fontes de apoio para a maioria. Os resultados deste trabalho ampliam a possibilidade de se investigar, por exemplo, os motivos que levam os docentes a não solicitarem apoio mediante os casos de indisciplina.

PALAVRAS-CHAVE: indisciplina, gestão compartilhada, curso técnico integrado, ensino médio.

\section{HOW TEACHERS OF TECHNICAL INTEGRATED COURSES SHARE THE MANAGEMENT OF INDISCIPLINE}

\begin{abstract}
The indiscipline is a factor present in the educational field and for having a complexity of causes that provide it, it requires a joint effort of all educational actors. Therefore this field research and explanatory aims to investigate, through a questionnaire, as teachers who teach in Integrated Technical Courses to High School in Federal Institute of Education, Science and Technology of Paraiba - Campus Campina Grande manage indiscipline in the classroom, more specifically as is the shared management the unruly behavior of students in the classroom between teachers, other sectors and with
\end{abstract}

educational staff of this institution. The results show that most of the investigated teachers not seek help to deal with indiscipline issues, and for those who usually ask for help, they do only rarely, and the Pedagogical Coordination, the Coordination of Assistance for Students and the Educational Assistants are the major sources of support for the most of them. The results of that work increase the possibility of investigating, for example, the reasons that lead teachers to not request support before the cases of indiscipline.

KEYWORDS: Indiscipline, shared management, integrated technical course, high school. 


\section{INTRODUÇÃO}

Este trabalho apresenta parcialmente os resultados da pesquisa intitulada "A Gestão da Indisciplina em Sala de Aula pelos Professores dos Cursos Técnicos Integrados do Instituto Federal de Educação, Ciência e Tecnologia da Paraíba (IFPB) - Câmpus Campina Grande", fomentada pelo Programa de Bolsas de Iniciação Científica e Tecnológica da Pró-Reitoria de Pesquisa do IFPB, cujo objetivo central é investigar como os docentes que lecionam nos Cursos Técnicos Integrados ao Ensino Médio gerenciam a indisciplina em sala de aula.

A justificativa de se pesquisar o tema indisciplina pode ser identificada quando se observa que o comportamento que foge as regras disciplinares é um fato compartilhado por praticamente todas as instituições de ensino e este interfere fundamentalmente com o objetivo primordial de todos os que compõem o espaço educacional que é o processo ensino-aprendizagem. Portanto, apresentam-se dois estudos que exemplificam esse problema.

Numa investigação com 68 docentes que lecionam no Ensino Técnico Integrado ao Nível Médio do IFPB - Câmpus Campina Grande sobre a interferência da indisciplina em sala de aula no trabalho destes, observou-se que $97 \%$ dos docentes afirmaram que a indisciplina intervém no trabalho que executam (Rodrigues, Marques \& Gomes, 2012). De modo complementar, Aquino (2011) num estudo longitudinal sobre os registros de ocorrências disciplinares referentes a seis turmas de Ensino Médio de uma escola na cidade de São Paulo apresenta que, entre os anos de 2003 e 2004, 38\% dos alunos estiveram envolvidos com episódios disciplinares, chegando a 70\% de casos de indisciplina em 2007.

Mediante a esta problemática, este artigo se propõe a investigar como ocorre a gestão da indisciplina pelos docentes que lecionam nos cursos técnicos integrados ao ensino médio do IFPB - Câmpus Campina Grande, especificamente como ocorre a gestão compartilhada do comportamento indisciplinado entre professores, demais setores e agentes educacionais.

Este trabalho contribui para o entendimento de como funciona a rede de apoio ao docente no IFPB - Câmpus CG, especificamente no caso da administração da indisciplina, e permite as Coordenações que assessoram a atividade docente avaliem a eficácia das suas ações.

\section{INDISCIPLINA ESCOLAR: CONCEITOS, CAUSAS, RELAÇÃO PROFESSOR E ALUNO E A RESPONSABILIDADE COMPARTILHADA}

A função da disciplina é muitas vezes questionada, percebida como forma de repressão, contudo Comte-Sponville (1998, p.16) revela a importância da polidez, resultante da educação para os limites, como essencial para o processo de humanização:

A polidez [...] é anterior à moral [...] a qual se constituirá pouco a pouco, como uma polidez interiorizada, livre de aparências e de interesses, toda concentrada [...]. Mas como essa moral emergiria, se a polidez não fosse dada primeiro? As boas maneiras precedem as boas ações e levam a estas.

Sendo a disciplina fator necessário para o convívio humano, igualmente a definição do seu 
antônimo, indisciplina, é essencial na gestão desta. Estrela (1992) comenta sobre a complexidade de se estudar a indisciplina apontando, como exemplo, a definição polissêmica deste vocábulo, pois, por exemplo, este pode significar matéria de estudo, punição, regra e obediência para reinar a ordem num determinado grupo. Então, é necessário levar em consideração que o conceito de disciplina varia de acordo com o contexto histórico e cultural de cada sociedade, a qual sempre trata da disciplina conforme os padrões em vigor no que diz respeito à função que é dada à escola (Estrela,1992).

Já Parrat - Dayan (2009), enfatizando o aspecto comportamental e as relações sociais, define a indisciplina como uma infração ao regulamento interno, uma falta de civilidade e uma agressão às boas maneiras e, principalmente, a manifestação de um conflito.

Sobre os fatores que propiciam a indisciplina, Vasconcellos (1997) assinala que esta é um processo que agrega muitas causas: o desinteresse do aluno proveniente, por exemplo, da influência midiática externa ao ambiente escolar, que é geralmente mais atrativa que a escola; a família que não cumpre com o papel de educar para os limites; a escola que não apoia o professor pedagogicamente e a influência da desorganização da sociedade. O autor aborda também os motivos que influenciam o desinteresse e consequentemente o comportamento sem disciplina pelos alunos na contemporaneidade: a crise atual de sentido na educação que se reflete no comportamento dos discentes em sala de aula, pois antigamente se obedecia mais facilmente às normas disciplinares, porque se almejava um futuro profissional resultante da educação formal. $\mathrm{Na}$ atualidade, esse significado perdeu o valor, já que existem muitas pessoas formadas sem trabalho ou mal - remuneradas.

O sentido atribuído ao estudo é também investigado por Dourado et al. (2010) e revela a contradição dos jovens sobre este tema. Numa escola de Ensino Médio de Campina Grande, 20 estudantes participaram de encontros que objetivavam ampliar a percepção destes sobre os projetos de vida. Durante os encontros percebeu-se que os valores mais apreciados eram referentes às experiências e vivências momentâneas e não aqueles relacionados ao futuro profissional, apesar de a maioria dos estudantes apresentarem paradoxalmente como propósito de vida a realização profissional. Mas como alcançar o sucesso profissional sem uma reflexão sobre as atitudes dentro da escola e, mais especialmente, na sala de aula no que se refere à questão da disciplina e valorização da educação formal?

Desta forma, percebe-se, claramente, a importância dos educadores e da instituição educacional como propiciadores de direcionamento aos jovens para o encontro do sentido sobre a educação formal.

Antunes (2010), assim como Vasconcelos (1997), tratam sobre os focos facilitadores do comportamento indisciplinado do aluno em sala de aula e apontam a escola, o professor e a interação deste com o aluno como pontos fundamentais nessa temática. Nesta perspectiva multifatorial insere-se a gestão compartilhada.

Apropriando-se do conceito de gestão explicitado por Barceló e Guillot (2013, tradução nossa) que definem gestão como a organização de recursos para a obtenção de um resultado de modo eficiente e efetivo, a gestão compartilhada da indisciplina refere-se à organização de 
recursos por parte dos docentes e demais atores educacionais, sejam eles equipe técnica, direção, pais e os próprios discentes, para que o comportamento do discente interfira de modo assertivo com o processo de ensino-aprendizagem. Pontua-se, então, que o que se pretende com gestão compartilhada da indisciplina não se refere ao comportamento de docilidade e domesticação por meio da punição, como ressalta Foucault (2004), mas ao melhor desempenho na aprendizagem e no exercício da formação cidadã, como defende Lück (2009).

Na relação professor e aluno, para que o educador possa conduzir a disciplina em sala de aula, Antunes (2009) apresenta habilidades intra e interpessoais que o professor deve exercitar para apropriar a técnica de gerenciamento da indisciplina nos moldes em que ela ocorre atualmente: aceitar com bom humor as diferenças entre as pessoas; distinguir o essencial do supérfluo; saber ouvir antes de julgar o aluno; colocar-se no lugar do outro; admitir quando estiver errado; perceber que quando os alunos são chamados para tratar sobre o comportamento indisciplinado, geralmente respondem com irritação e insegurança; compreender que nem todos precisam corroborar com a ideia do educador; reavaliar os casos de indisciplina e aplicar medida disciplinar com seriedade, rapidez e justiça.

Enfatiza-se, deste modo, a complexidade que compõe a indisciplina em sala de aula, e especialmente a responsabilidade da escola e do docente no gerenciamento do comportamento indisciplinado em sala de aula. Nesse contexto multifatorial revela-se, não somente, mas também a participação essencial do professor na gestão disciplinar. Essa participação requer muito deste profissional o qual muitas vezes não possui as ferramentas adequadas para o manejo desta questão tão complexa. Pires (1999) afirma que o docente, às vezes por comodismo próprio, por falta de apoio da escola ou por deficiência na formação acadêmica, não se encontra preparado psicologicamente para receber os impactos inevitáveis e problemáticas características de sua profissão.

No que tange à responsabilidade da escola na administração da indisciplina discente, a Cartilha de Orientações sobre Como Proceder Frente à Indisciplina Escolar (Goiás, 2010) na seção que sugere um modelo de Regimento Escolar para as instituições de ensino, trata sobre o Núcleo Pedagógico Escolar composto pelo Coordenador Pedagógico, Pedagogo, Assistente Social e Psicólogo que tem como objetivo a promoção e o assessoramento nas atividades de natureza técnico - científica e pedagógica de modo integrado com a comunidade escolar. Dentre as competências deste núcleo, pode-se citar: a promoção da integração entre escola, família e comunidade; o fornecimento de subsídios aos docentes para a melhoria do processo ensinoaprendizagem e a informação, de modo contínuo, aos pais e responsáveis sobre a frequência e o rendimento dos educandos, assim como a execução da proposta pedagógica da escola. Observa-se a importância deste como representação da escola, no papel de facilitador do processo ensinoaprendizagem, neste caso como corresponsável pela gestão da indisciplina escolar. No IFPB, a Coordenação Pedagógica (COPED) e a Coordenação de Assistência ao Estudante (CAEST) exercem funções similares ao Núcleo Pedagógico proposto.

Ainda, esta cartilha propõe que os casos de indisciplina escolar devem ser tratados administrativamente pela escola, aplicando as sanções previstas no Regimento Escolar e só em último caso devem ser encaminhados ao Conselho Tutelar ou à Promotoria da Justiça da Infância e 
da Juventude, para os devidos fins (Goiás, 2010). Portanto, no âmbito do IFPB - Câmpus Campina Grande, compete à COPED a apuração e os devidos encaminhamentos após o registro do ato indisciplinado apresentado pelos docentes.

Phelan e Schonour (2009) no capítulo intitulado Política Administrativa e de Apoio ao Professor, relatam a experiência de um ex-diretor escolar o qual considera que os diretores e os professores devem estar disponíveis para encaminhar os estudantes ao gabinete (Núcleo Pedagógico ou Coordenação Pedagógica no caso do Câmpus Campina Grande), somente quando os docentes tiverem exauridos todos os recursos para a mudança de comportamento do estudante indisciplinado.

Depreende-se que, mediante a complexidade de atuação do professor, da escola e demais atores educacionais para gerenciar a indisciplina em sala de aula, ambos precisam exercitar a virtude da humildade, quando se trata da gestão compartilhada da indisciplina. Comte-Sponville (1998) define humildade como:

A humildade não é a depreciação de si, ou é uma depreciação sem falsa apreciação. Não é ignorância do que somos, mas, ao contrário, conhecimento, ou reconhecimento, de tudo o que não somos. É seu limite [...] É a virtude do homem que sabe não ser Deus. (ComteSponville, 1998, p. 153).

Nesta conjuntura, na qual professor e escola precisam interagir na gestão da indisciplina escolar, torna-se imperativo a investigação da relação entre corpo docente, a equipe pedagógica e os demais profissionais da educação, a respeito da administração compartilhada do comportamento indisciplinado do discente.

\section{METODOLOGIA}

Esta pesquisa se caracteriza como de campo, que de acordo com Severino (2007) nesta modalidade de pesquisa a coleta dos dados é feita nas condições naturais em que os fenômenos ocorrem, sendo assim diretamente observados, sem intervenção e manuseio por parte do pesquisador.

Outra característica deste estudo consiste na pesquisa explicativa, que na visão de Andrade (2002) procura aprofundar o conhecimento da realidade na medida em que visa à identificação dos fatores determinantes dos fenômenos estudados.

Para a coleta de dados, foram utilizados questionários com questões abertas e fechadas, voltadas ao gerenciamento da indisciplina pelo professor. Os objetivos de estudo e a literatura selecionada serviram de base para a elaboração deste instrumento. Estes foram aplicados no segundo semestre do ano de 2012. A amostragem desse estudo constituiu-se de um grupo de 68 professores, dentre a população de 95 docentes que lecionavam nos Cursos Técnicos Integrados ao Ensino Médio do IFPB - Câmpus Campina Grande no referido ano letivo.

Em relação ao método utilizado para analisar as respostas dos questionários, aplicou-se a Análise de Conteúdo. Dentre os domínios possíveis de utilização desse método, Bardin (2016) 
apresenta, em sua obra, um quadro no qual se pode destacar, por exemplo, todas as comunicações escritas dentro de um grupo restrito, cartas, respostas a questionários e trabalhos escolares como passiveis de serem aferidos por este método. Esse método permite o tratamento descritivo dos dados de forma sistemática e objetiva, análise quantitativa, e a interpretação destes, análise qualitativa (Bardin, 2016).

Esta pesquisa foi analisada pelo Comitê de Ética do Instituto Federal de Educação, Ciência e Tecnologia da Paraíba, de acordo com o protocolo de pesquisa C.G. 004/2011, e aprovada no dia 21 de dezembro de 2011.

\section{RESULTADOS E DISCUSSÃO}

Nesta seção apresentam-se e discutem-se os resultados das questões referentes ao compartilhamento da gestão da indisciplina executado pelos docentes investigados, mais especificamente se eles compartilham a gestão da indisciplina, com que frequência ocorre, quais os setores que estão envolvidos nesse processo e de que modo ocorre essa solicitação.

Buscou-se investigar se, no desempenho de gestão de casos de indisciplina, os docentes investigados costumam solicitar ajuda. Os resultados desta consulta são apresentados na Figura1.

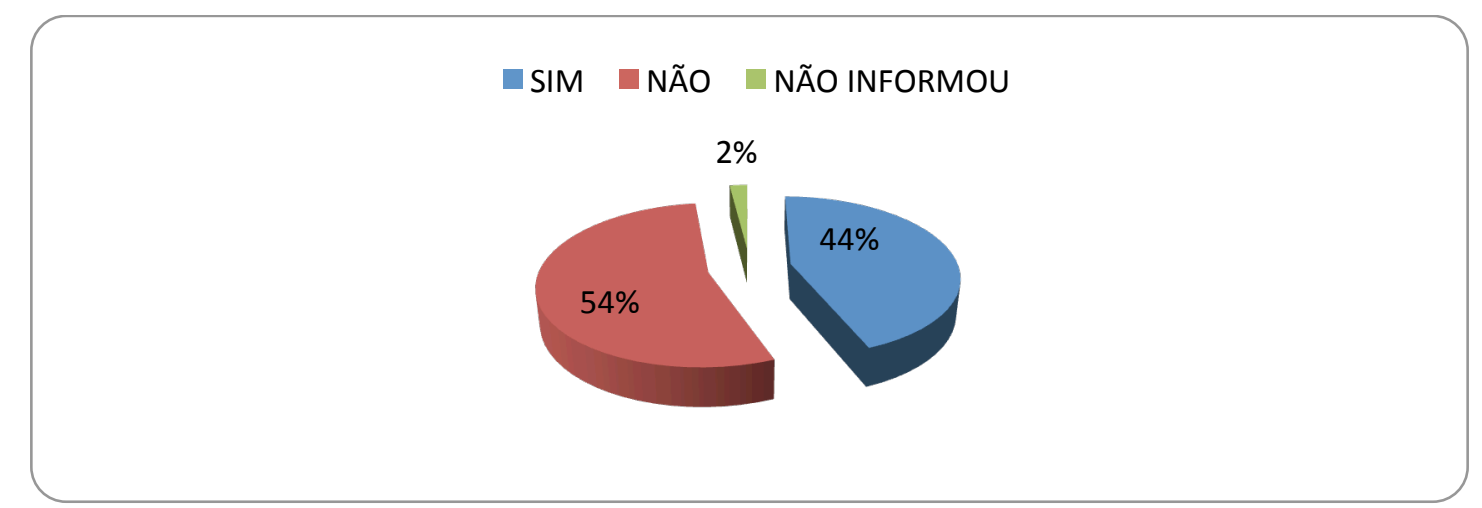

Figura 1- Quantitativo de docentes que costumam pedir ajuda para o gerenciamento da indisciplina Fonte: Questionário

Pode-se observar que um pouco mais da metade dos professores investigados (54\%) não costuma pedir ajuda para a administração da indisciplina. Desta forma, percebe-se que estes profissionais, na sua maioria, não pactuam a responsabilidade da administração disciplinar com outros atores institucionais. Conjectura-se que os docentes possam se sentir preparados para tal função, de modo que os casos de indisciplina possam ser resolvidos no espaço da sala de aula. Essa hipótese está relacionada à outra pergunta feita aos participantes que buscava identificar a percepção de estarem preparados para gerir a indisciplina em sala de aula. Nesta identificou-se que $90 \%$ dos professores afirmaram estarem preparados para gerir a indisciplina em sala de aula.

Entretanto, esse resultado vai de encontro ao de outro item investigado que mostra que os mesmos professores não têm formação, em sua maioria (78\%), para gerenciar a indisciplina em sala de aula. Nesse aspecto, Parrat - Dayan $(2009$, p.94) comenta sobre a falta de formação do 
docente para lidar com questões de indisciplina e como esta pode afetar a gestão da indisciplina: "[...] trabalhar a partir de um conflito é uma ferramenta importante para prevenir ou remediar a indisciplina. Evidentemente, esse trabalho precisa de uma formação específica do professor que, muitas vezes, age de maneira improvisada". Nota-se que se torna difícil administrar as relações interpessoais, neste caso os comportamentos indisciplinados, de modo isolado e muitas vezes sem capacitação para lidar com as relações interpessoais.

Outro ponto a ser discutido se refere à troca de informações entre docentes e equipe técnica. Neste caso, quando o professor não compartilha a gestão da indisciplina com a equipe técnica (a COPED e a CAEST no âmbito do IFPB - campus Campina Grande), muitas vezes o acompanhamento dos discentes torna-se falho, dificultando o trabalho para o desenvolvimento das potencialidades dos estudantes a tempo de contribuir de modo significativo com o rendimento acadêmico, a formação cidadã e a aprovação deste no período destinado ao ano letivo regulamentar. Muitas vezes a partilha desses casos só ocorre nos Conselhos de Classe $^{1} \mathrm{e}$ quando estes não tem a frequência bimestral ou semestral, inviabilizam o trabalho sobre a rotina de estudo e relações interpessoais dos discentes, por exemplo.

Ademais, o Regulamento Disciplinar para os Discentes dos Cursos Técnicos Integrados do IFPB (2011) divide as ações indisciplinadas dos discentes em três tipos: leves, graves e gravíssimas. Deduz-se que para que um professor não solicite ajuda na gestão da indisciplina todas as faltas disciplinares que ele presenciar em sala de aula devem ser leves, não repetidas, pois a repetição delas eleva a gravidade da mesma, sendo necessário, então, o encaminhamento do discente à COPED e o atendimento do caso em equipe interdisciplinar (incluindo o docente); experiência no trato com situações similares; boa habilidade nas relações interpessoais, além do mais o docente deve estar bem consigo mesmo em todas as situações que precisar gerenciar.

Para os docentes que alegaram solicitar auxílio em questões disciplinares, procurou-se identificar a frequência de solicitação desta assistência, o que se evidencia na Figura 2.

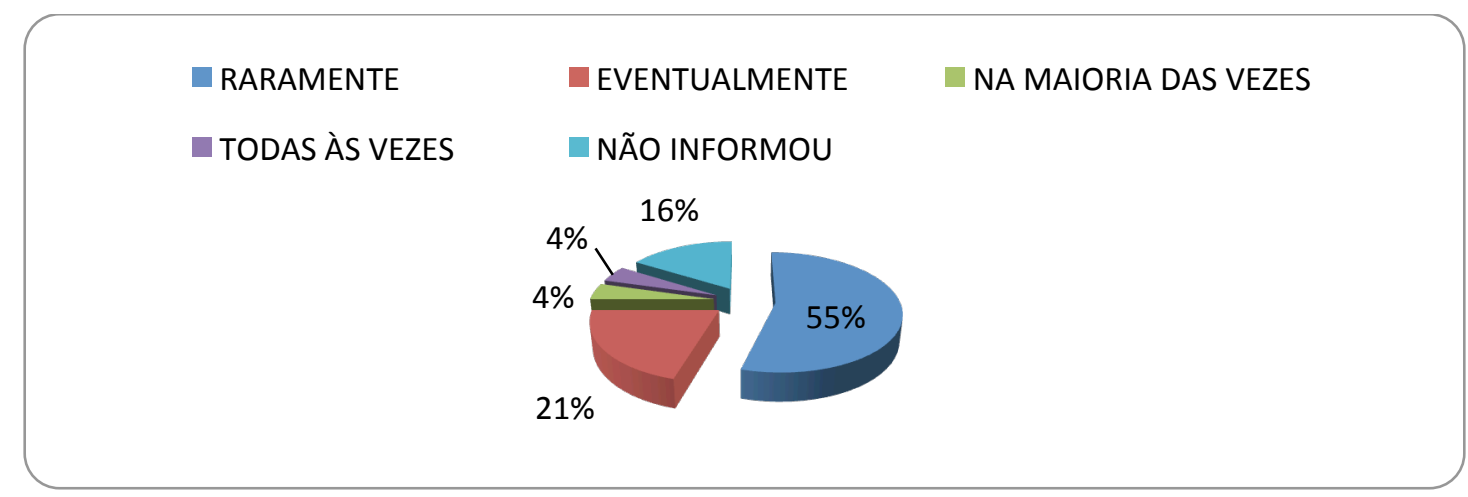

Figura 2- Frequência de solicitação de ajuda para casos de indisciplina

Fonte: Questionário

\footnotetext{
${ }^{1}$ Os Conselhos de Classe consistem em reuniões entre corpo docente, Direção de Ensino e a COPED e a CAEST que abordam o desempenho dos estudantes e estratégias de enfrentamento para os problemas identificados, além de que, no caso do Conselho de Classe Final, avaliam e deliberaram sobre a retenção na série ou aprovação dos discentes que não obtiveram nota suficiente para a progressão nas séries, de acordo com critérios qualitativos.
} 
As informações demonstradas na figura 1 destacam que a solicitação de ajuda dos docentes para outros setores/pessoas para colaborar com o gerenciamento da indisciplina em sala de aula não é muito frequente, tendo $55 \%$ dos docentes que responderam que raramente pedem ajuda, 21\% relatou que eventualmente pede auxilio a outros setores e uma pequena parcela expôs que na maior parte das vezes (4\%) e sempre pede apoio a outros setores (4\%). Logo, observa-se que até mesmo os professores que costumam solicitar auxílio na gerência da indisciplina, estes preferem gerir a indisciplina com os próprios recursos, ao invés de solicitar auxílio, na maioria das vezes. Pode-se observar, também, que $16 \%$ não informaram a frequência em que pedem auxilio a outros setores.

É sabido que nem sempre a relação entre docentes e equipe técnica/gerencial é satisfatória. Zagury (2009), em pesquisa com docentes de todo o país, identificou que estes consideram que as suas opiniões são mais respeitadas e consideradas pelos colegas do que pela equipe técnica e gerencial, pois, para a autora, estes últimos, muitas vezes, consideram os professores como executores, e não como pensadores do processo educativo, deste modo as opiniões deles não precisam ser ponderadas.

Não obstante a essa percepção sobre a equipe técnica e gerencial, Freire (1996) ressalta a necessidade de o próprio docente avaliar como se dá a relação entre ele e os demais atores educacionais, para que não haja um fechamento em si mesmo:

O preparo científico do professor ou da professora deve coincidir com sua retidão ética. É uma lástima qualquer descompasso entre aquela e esta. Formação científica, correção ética, respeito aos outros, coerência, capacidade de viver e de aprender com o diferente, não permitir que o nosso mal-estar pessoal ou a nossa antipatia com relação ao outro nos façam acusá-lo do que não fez são obrigações a cujo cumprimento devemos humilde mas perseverante nos dedicar. (Freire, 1996, p. 16-17).

Até que ponto o fato da pouca procura de auxílio representa um fechamento em si mesmo, a falta de interesse da equipe técnica e gerencial em escutar e valorizar os docentes, ou a habilidade em administrar as relações em sala de aula se configuram como incógnitas a serem investigadas em pesquisas posteriores.

O setor ou servidor/setor/funcionário para o qual é solicitado auxílio por parte dos docentes é o resultado informado na Figura 3. 


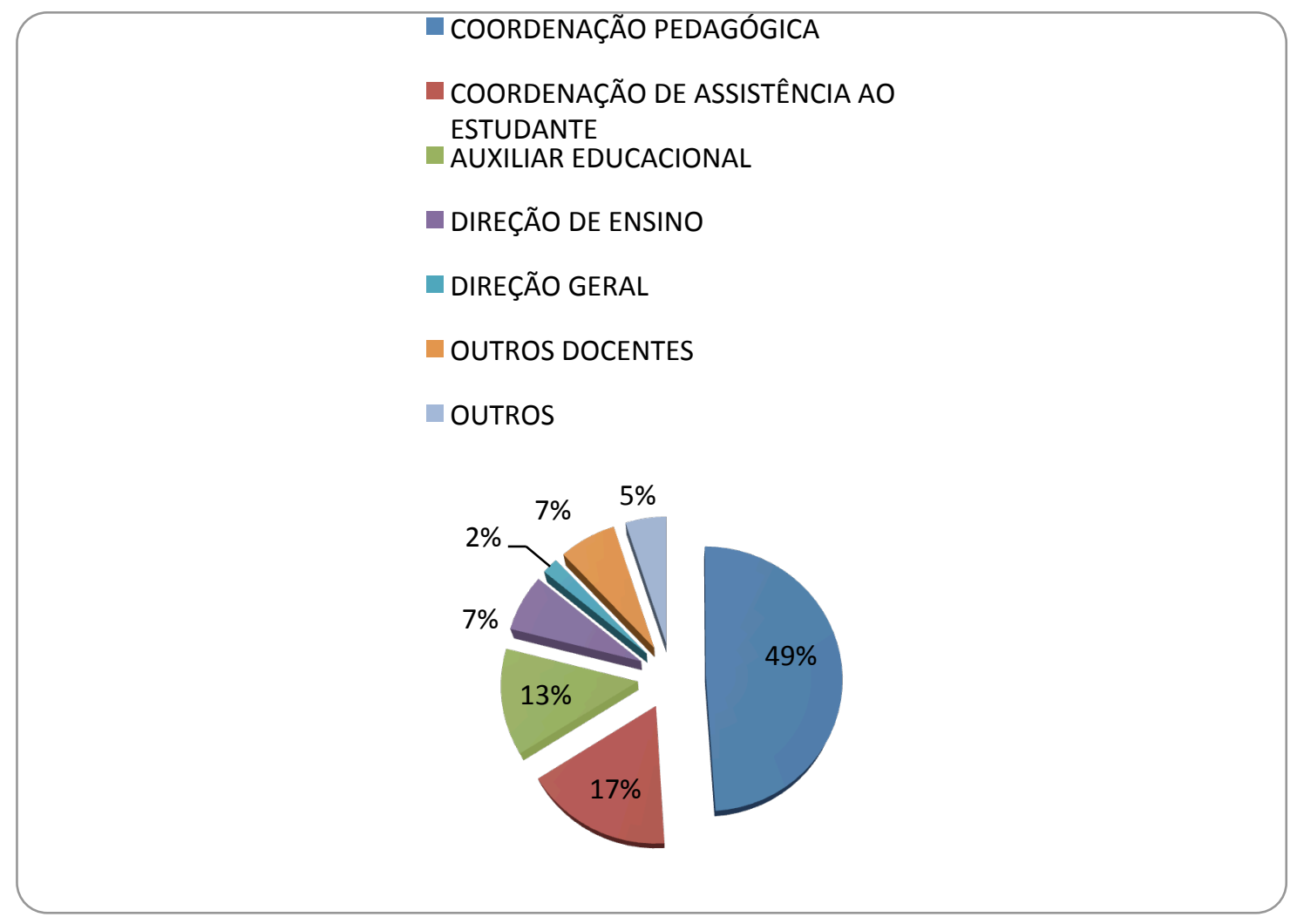

Figura 3 - Setor/servidor/prestador de serviço para o qual as solicitações de ajuda para questões disciplinares são feitas

Fonte: Questionário

Observa-se que o setor mais solicitado para auxilio em questões disciplinares pelo professor é a COPED com 49\%; demais professores elegem o apoio da CAEST (17\%); outros $13 \%$ optam pela ajuda das Auxiliares Educacionais (prestadoras de serviço que tem função similar aos Assistentes de Alunos - servidores do quadro efetivo que até o momento da pesquisa não havia alguém a exercer este cargo neste Câmpus - que é a de propiciar apoio acadêmico nas atividades desenvolvidas no Câmpus e a intercomunicação entre os diversos setores, profissionais e estudantes) para encaminhar o discente até outro setor, e uma minoria escolhe a Direção de Ensino (7\%), outros docentes (5\%) e a Direção Geral (2\%) como opções de encaminhamento.

A Coordenação Pedagógica exerce a função da Coordenação de Turno, devido à inexistência, no Câmpus em questão, desta última, que tem a função de fiscalizar e aplicar as medidas disciplinares de advertência verbal, ou encaminhar os casos mais graves para o Conselho Disciplinar, de acordo com o Regulamento Disciplinar do IFPB (2011). Então, os docentes demonstram preferência a este setor como local para encaminhamentos de alunos envolvidos com indisciplina em sala de aula.

Possivelmente a CAEST tenha sido citada na segunda maior proporção devido a, em passado recente, a COPED e a CAEST terem sido uma coordenação única - Coordenação Técnico Pedagógica e de Apoio ao Estudante (COTEP) - e até o presente momento, mesmo com funções diversas, ainda dividirem o mesmo espaço físico e realizarem atividades de cunho psicopedagógico e social em conjunto. Por exemplo, quando uma questão disciplinar chega à CAEST, ela é 
direcionada à COPED, mas, muitas vezes, os processos de apuração e resolução são feitos em parceria por estas duas coordenações.

As Auxiliares Educacionais se apresentam como terceira fonte de direcionamento. Estas se configuram como suporte aos docentes e às coordenações mencionadas no acompanhamento dos discentes, principalmente, nas atividades que necessitem o deslocamento fora de sala de aula.

Como o IFPB tem uma estrutura hierarquizada, com várias coordenações e direções, é raro que essa hierarquia seja quebrada e um caso de indisciplina seja encaminhado diretamente para as direções, como se observa no resultado deste ponto.

O Regulamento Disciplinar (2011) não delega ao docente o exercício da função punitiva, apesar de estar claro neste documento que ele deva ser respeitado no desempenho de sua função. Portanto, quando os docentes respondem que pedem ajuda aos colegas sobre questões disciplinares, supõe-se que, por exemplo, esse auxílio possa ser um apoio psicossocial num momento de angústia, ou uma sugestão sobre como gerenciar a indisciplina.

$\mathrm{Na}$ Figura 4, estão expressos os modos como os professores executam as solicitações de auxílio sobre as questões disciplinares.

- AUSENTA-SE DA SALA PARA PROCURAR OUTRO SETOR/PROFISSIONAL

- SOLICITA A AUXILIAR EDUCACIONAL PARA ENCAMINHAR O ESTUDANTE PARA OUTRO SETOR

- SOLICITA A AUXILIAR EDUCACIONAL PARA CHAMAR OUTRO PROFISSIONAL ATÉ A SALA DE AULA

च ESPERA O TÉRMINO DA AULA E PROCURA OUTRO PROFISSIONAL/SETOR

- JUNTO COM OS ESTUDANTES PROCURA OUTRO PROFISSIONAL/SETOR

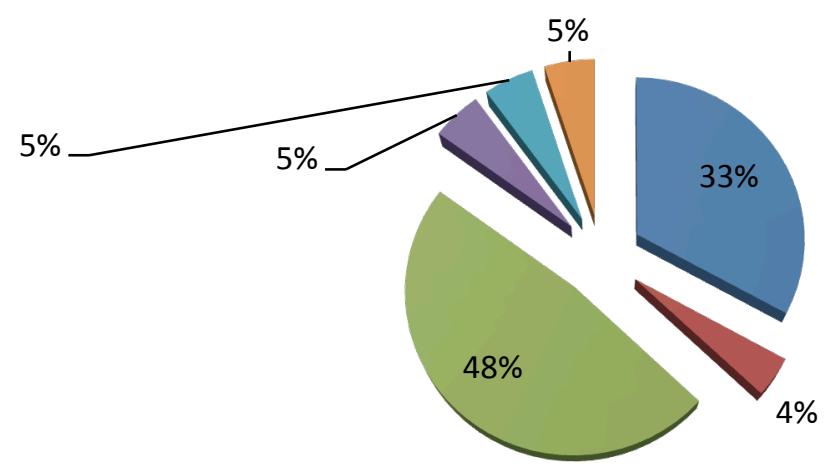

Figura 4 - Ações executadas pelos docentes para solicitar ajuda com questões disciplinares Fonte: Questionário

A Figura 4 mostra que a maioria dos professores (48\%) costuma solicitar as Auxiliares Educacionais para chamar outro profissional até a sala em que se encontram, enquanto que outra 
parcela (33\%) se ausenta da sala para procurar ajudar. Os demais docentes se dividiram em três grupos cujos números são praticamente equivalentes: esperam o término da aula e procuram outro professor ou setor que os auxiliem (5\%); junto com os estudantes procuram outro profissional ou setor para tratar do assunto (5\%), ou solicitam que a Auxiliar Educacional encaminhe o discente indisciplinado para outro setor (4\%). A menor parcela dos docentes (4\%) citou que utilizam outros meios para solicitar ajuda no gerenciamento da indisciplina.

Infere-se desse resultado que, dentre os docentes que solicitam auxílio para tratar de questões de indisciplina em sala de aula, há a preferência da maior parte (58\%) pelo auxílio de profissionais que se dirijam até a sala de aula para dar suporte ao docente, por meio, principalmente, da solicitação às Auxiliares Educacionais, deste modo, não procuram, previamente, com o auxílio de outros profissionais, discutir os casos de indisciplina para uma intervenção posterior, mas uma intervenção pontual. Outra questão a se discutir se destaca pela interferência de outro educador na questão disciplinar que ocorre durante a aula em questão. Se o docente necessita de apoio de terceiros, conjectura-se que para que este solicite a ajuda de uma "autoridade" externa haja um despreparo deste para lidar com a situação, ou então que o caso seja grave, pois quando outro profissional entra no espaço do docente a autoridade deste educador pode ser abalada, como salientam Phelan e Schonour (2009).

Outra reflexão equivalente é a de que o segundo maior grupo de docentes afirma deixar a sala de aula para procurar auxílio sobre situações disciplinares. Pressupõe-se, também, que, por exemplo, para um docente ausentar-se da sala a situação seja percebida como grave ou pela falta de preparo sobre a gestão da indisciplina.

A respeito do caso de que alguns professores afirmam receber a ajuda de estudantes para que estes busquem auxílio para este profissional, cabe esclarecer que no IFPB - Câmpus Campina Grande existe a figura do Representante de Turma, que é um discente escolhido por votação dos pares para intercomunicar a turma com os demais agentes educacionais e setores da instituição, assim sendo, hipotetiza-se que a esse estudante seja delegada, preferencialmente, a função de auxiliar o docente nestes casos.

\section{CONSIDERAÇÕES FINAIS}

A disciplina em sala de aula transcende a percepção limitada de que ela é sinônimo de ausência de liberdade dos estudantes, mas se apresenta como veículo que propicia o funcionamento satisfatório das relações interpessoais. Ela é um acontecimento constante no cotidiano da educação formal e o trabalho para a gestão desta é fundamental, pois sendo esta propiciada por vários fatores, torna a sua administração complexa e o trabalho em equipe essencial para geri-la.

Mesmo as relações interpessoais, mais especificamente a disciplina discente, sendo uma responsabilidade a ser compartilhada entre vários atores educacionais, inclusive pelos próprios discentes, esta pesquisa elucida que a maior parte os professores investigados não atuam de maneira partilhada quando tratam de casos de indisciplina, e que quando esta é compartilhada, 
ocorre principalmente para a solução de casos pontuais. Outro ponto mostra que a Coordenação Pedagógica, a Coordenação de Assistência ao Estudante e as Auxiliares Educacionais são as principais fontes de apoio para os docentes que costumam solicitar apoio frente aos casos de indisciplina.

Os resultados deste trabalho apontam para novas possibilidades de investigações como, por exemplo, sobre o porquê da opção da maioria dos docentes não procurar auxílio sobre as questões disciplinares, qual o impacto na resolução dos casos de indisciplina quando outro profissional vai até a sala para auxiliar o professor, assim como a investigação da razão de alguns professores se ausentam em sala de aula para solicitar ajuda em casos de disciplina, mesmo perante a existência de outras alternativas.

\section{REFERÊNCIAS}

Andrade, M. M. de. (2002). Como Preparar trabalhos para cursos de Pós-Graduação: noções práticas. (5a ed.) São Paulo: Atlas.

Antunes, C. (2010). Professores e Professauros: reflexões sobre a aula e práticas pedagógicas diversas (4a ed.) Petrópolis, Rio de Janeiro: Vozes.

Antunes, C. (2009). Professor bonzinho = aluno difícil: a questão da indisciplina em sala de aula (7a ed.) Petrópolis, RJ: Vozes.

Aquino, J. G. Da (contra)normatividade do cotidiano escolar: problematizando discursos sobre a indisciplina discente. (2011). Cadernos de Pesquisa. 41(143), 456-484. doi: http://dx.doi.org/10.1590/S0100-15742011000200007.

Barceló, M., \& Guillot, S. (2013). Gestión de proyectos complejos: una guia para la inovación y el empreendimento. Madrid: Ediciones Pirámide.

Bardin, L. (2016). Análise de conteúdo (3a reimp. da 1a ed.). Lisboa: Edições 70.

Comte-Sponville, A. (1998). Pequeno tratado das grandes virtudes (1a ed., 7a. Tiragem). São Paulo: Martins Fontes.

Dourado, E. T. S., de Figueirêdo, A. T. B., de Farias, E. C. S., Damásio, B. F., de Aquino, T. A. A., \& da Silva, J. P. (2010). Educar para o sentido: uma intervenção prática. In B. F., Damásio, J. P. Silva; T. A. A. Aquino. (Orgs.) Logoterapia e Educação. São Paulo: Paulus. 
Estrela, M. T. (1992). Relação pedagógica, disciplina e indisciplina na aula. Portugal: Porto Editora.

Foucault, M. (2004). Vigiar e Punir (29a ed.) Petrópolis: Vozes.

Freire, P. (1996). Pedagogia da Autonomia: saberes necessários à prática educativa. São Paulo: Paz e Terra.

Goiás (Estado). Ministério Público (2010). Como Proceder Frente à Indisciplina Escolar - Cartilha de Orientações. Escola Superior do Ministério Público do Estado de Goiás. Goiânia.

Instituto Federal de Educação, Ciência e Tecnologia da Paraíba. (2011). Regulamento Disciplinar para o Corpo Discente - Cursos Técnicos Integrados ao Ensino Médio. Recuperado de http://www.ifpb.edu.br/reitoria/pro-reitorias/pre/regulamentos-

disciplinares/Regulamento\%20Disciplinar\%20-\%20Integrado\%20-\%20Versao\%20final.pdf/view.

Lück, H. (2009). Dimensões de gestão escolar e suas competências. Curitiba: Positivo.

Parrat- Dayan, S. (2009). Como enfrentar a indisciplina na escola. São Paulo: Contexto.

Phelan, T. W., \& Schounour, S. J. (2009). 1, 2, 3 - mágica para professores - disciplina efetiva em sala de aula. Porto Alegre: Artmed.

Pires, D. B. (1999). Disciplina: construção da disciplina consciente e interativa em sala de aula e na escola. Educação \& Sociedade, 20(66), 181-185. Recuperado de http://www.scielo.br/scielo.php?script=sci_arttext\&pid=S0101-

73301999000100009\&lng=en\&nrm=iso\&tlng=pt.

Rodrigues, I. A. de A., Marques, L. C., \& Gomes, M. M. C. (2012). Como a Indisciplina em Sala de Aula Interfere no Trabalho Docente. Revista Principia, 20.

Severino, A. J. (2007). Metodologia do trabalho científico. (23a ed. rev. e atual.) São Paulo: Cortez.

Vasconcellos, C. dos S. (1997). Os desafios da indisciplina em sala de aula e na escola, 28, FDE. Recuperado de http://www.crmariocovas.sp.gov.br/pdf/ideias_28_p227-252_c.pdf. 
Zagury, T. (2009). O professor refém: para pais e professores entenderem por que fracassa a educação no Brasil (9a ed.) Rio de janeiro: Record. 